\title{
Behavioural Change according to the Si/Al Ratio of Successive Na-Mordenites Observed through Their Dielectric Relaxation during Water Vapour Adsorption Process
}

\author{
Sekou Diaby \\ Laboratoire de Chimie-Physique, Unité de Formation et de Recherche en Sciences des Structures de la Matière et Technologie \\ (UFR-SSMT), Université FHB de Cocody, 22 BP 582, Abidjan 22, Côte d'Ivoire
}

Correspondence should be addressed to Sekou Diaby; sekoudiaby@yahoo.fr

Received 17 August 2015; Accepted 29 December 2015

Academic Editor: Yulin Deng

Copyright (C) 2016 Sekou Diaby. This is an open access article distributed under the Creative Commons Attribution License, which permits unrestricted use, distribution, and reproduction in any medium, provided the original work is properly cited.

\begin{abstract}
The experimental study of water vapour adsorption phenomenon on a zeolite, by dielectric relaxation measurement, makes it possible to determine the variations in the exchangeable cation hopping activation energy, on the surface of the solid, in relation to the number of adsorbed molecules. The present work shows that it is possible to explain the change observed in the energy, by means of simple assumptions based, on the one hand, on the models used in order to simulate the adsorption process and, on the other hand, on the distribution of the molecules adsorbed near the exchangeable cations. Thus, the phenomenological interpretation suggested here, about the change in the exchangeable cation hopping energy, obtained by dielectric relaxation measurement, makes us with a mind to conceive a simple method for explaining the results leading to new information on the organization of the first adsorbed molecules on the surface of the studied zeolite. Then, it can be verified that these conclusions confirm the assumptions already developed for interpreting the inferences from previous experiments carried out by means of other techniques.
\end{abstract}

\section{Introduction}

The study of gas-solid interfaces has been, for a long time, of great interest for the physical chemists. Indeed, it raises fundamental problems that show that the range of our understanding of the phenomena associated with the properties of solids is restricted. Coupled with that, it has potentially industrial application in various sectors. So understandably it has been giving rise to interest, since the beginning of the twentieth century, when microscopic descriptions appeared, with an aim of explaining the behaviour of the molecules during the adsorption process made in isothermal conditions. In the attempt to explain the phenomenon, the uses of purely heuristic concepts by the scientists and their expositions have not always been unquestionable and that prompts us to try new approaches, based on unprecedented experimental studies. In that context, every piece of findings, in the knowledge of the phenomena that happen on the surface of materials, can contribute significantly to explaining the recurring problem of the reactivity of the solids [1-3]. Thus, we studied the variations in the energy relating to the exchangeable cation hopping between the sites characterizing the zeolite surface. For the purpose, we tried to think out a method able to measure the modifications in the behaviour of the surface of solids, when they are submitted to the adsorption phenomenon. Indeed, previous works [4-8] show that it is possible to consider the adsorption process as a chemical reaction:

$$
\text { Vapour }+ \text { Solid } \Longleftrightarrow \text { Adsorbed-Phase }
$$

To evaluate the evolution of the solid's surface according to the amount of adsorbed vapour, we need to determine experimentally the performance of a characteristic property of the system, which varies with the course of the reaction. We opted for dielectric relaxation measurement in a sample kept in successive equilibrium states. In actual fact, the method consists in measuring, as accurately as possible, the variations of a parameter related to the surface structure and depending on the vapour pressure imposed on the system, at constant temperature. The work we did previously on the zeolites [9-12] moved us to examine a Na-mordenite 
submitted to various pressures on water vapour, while observing its electric properties.

\section{Materials and Methods}

2.1. Conditioning of the Sample. To study some hydrated samples of Na-mordenite, we shaped the zeolite into a solid disc conveniently sized to fit into the two conducting surfaces of a measuring capacitor. As it proceeded, we first compressed a powdered portion of the solid in an adapted mold under the pressure of $10^{8} \mathrm{~Pa}$ for 2 hours. Then the sample is fully hydrated, by keeping it for 48 hours in the atmosphere saturated with vapour emitted by a crystallizing dish, filled with water three times distilled in a silica assembling. The crystallizing dish is localized at the bottom of a watertight container wherein we put the sample. The whole set is kept at the constant temperature $(298 \mathrm{~K})$. At last, the fully hydrated sample is placed in the measuring device for dielectric relaxation measurement. The temperature (TT) of the set is held constant for 3 hours. At the end, the sample is in a state of hydration that can be approximately considered as an equilibrium state, even if it actually corresponds to a stationary state, where the number of the adsorbed water molecules can be considered constant. To verify that the number of the adsorbed water molecules on the solid, in this stationary state, does not vary, we repeated the experimental procedure by using the thermogravimetric technique, which, indeed, makes it possible to determine directly the sample mass. By the way, the thermogravimetry apparatus consists of an electronic microbalance whose mobile equipment is essentially composed of a beam jointed to a torsion ribbon tightened by two springs. At one end of the beam is fixed the stick bearing the crucible containing the sample. For the experiments, the solid is submitted to an adsorption process, and we observe growth in the mass. If we designate the initial mass of the sample by $m_{i}$ and its final mass by $m_{f}$, the relative variation in the mass $(\Delta m)$, expressed as a percentage, is equal to

$$
\Delta m=\frac{m_{f}-m_{i}}{m_{i}} \cdot 100 .
$$

Proceeding as already described, we obtained the results that enable us to calculate the mass of water molecules adsorbed onto each Na-mordenite sample (characterized by its $\mathrm{Si} / \mathrm{Al}$ ratio) as a function of the equilibrium temperature (TT). Then, we measured the corresponding dielectric losses.

\subsection{Experimental Measurements. Dielectric loss measure-} ments are performed on a sample previously prepared as described. The parameter in which we are interested in this type of experiment is the activation energy $\left(\Delta E_{\text {ex }}\right)$ that characterizes the cation hopping responsible for the dielectric losses. The relations between the cation hopping and the dielectric loss measurements have been described in detail, in a previous series of works [9-12]. To determine the activation energy, first we had to draw the change curve of the imaginary permittivity $\left(\varepsilon^{\prime \prime}\right)$ of the sample in relation to the frequency [13-18], at a given measuring temperature $(T)$. In order to avoid disrupting the equilibrium between the surface of

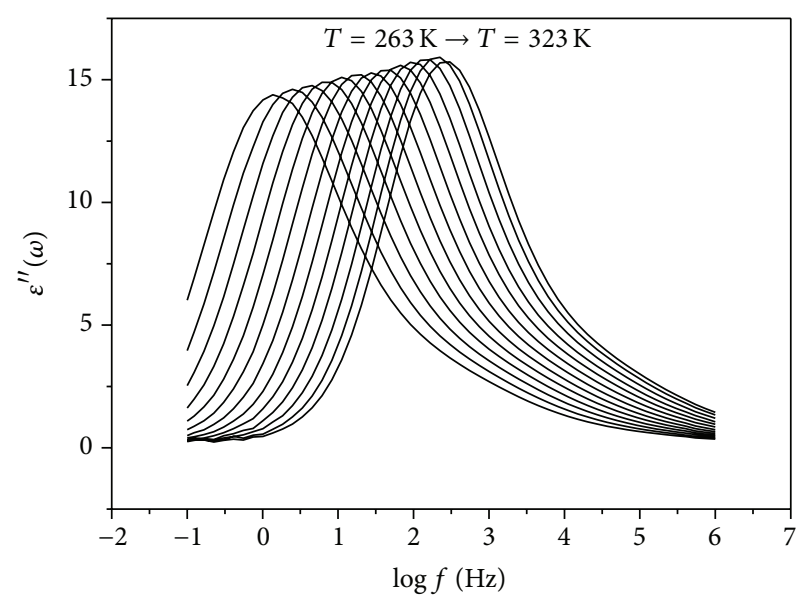

Figure 1: Plot of $\varepsilon^{\prime \prime}$ measurements depending on the frequency and at various temperatures $T, \varepsilon^{\prime \prime}$ being the imaginary part of the permittivity of a Na-mordenite characterized by its $\mathrm{Si} / \mathrm{Al}$ ratio and previously hydrated and kept at TT $=373 \mathrm{~K}$, for 3 hours.

the solid and the adsorbed molecules, we chose a range of temperatures, such as $T \leq \mathrm{TT}-50 \mathrm{~K}$. The measurements of the imaginary part $\left(\varepsilon^{\prime \prime}\right)$ of the dielectric permittivity thus obtained, according to the frequency of the electric field, are shown, as an example, in Figure 1.

Referring to Figure 1, the logarithm of the frequency measuring the maximum abscissa of each curve, characterized by a measuring temperature $T$, allows us to determine the most probable time $\left(\tau_{M}\right)$ of the polarization relaxation phenomenon that happens within the sample submitted to the experimental conditions, previously described. Indeed, the mathematical function that describes the variation of $\varepsilon^{\prime \prime}$ depending on the frequency has a maximum for

$$
\omega_{M} \times \tau_{M}=1 .
$$

By plotting each value determined from (3), on the curve characterized by a measuring temperature $(T)$, in relation to the ratio $(1 / T)$, we obtain a straight line whose slope leads to the energy $\left(\Delta E_{\mathrm{ex}, M}\right)$, by using the following relation:

$$
\ln \left(\tau_{M}\right)=\ln \left(\tau_{0}\right)+\frac{\Delta E_{\mathrm{ex}, M}}{k T} .
$$

An example of straight line thus obtained is shown with the diagram in Figure 2.

Proceeding as described, first we determined the energy $\left(\Delta E_{\mathrm{ex}}\right)$ values, by assessing them with a margin of error of $0.01 \mathrm{eV}$ [9-12] according to the equilibrium temperatures (TT) to which the Na-mordenite samples previously hydrated were successively submitted. Then, we were able to determine the degree of hydration of the Na-mordenite at each temperature (TT), thanks to the results obtained with the use of a thermobalance. And we elicited the values of the energy $\left(\Delta E_{\mathrm{ex}}\right)$ as a function of the number of adsorbed water molecules, for the considered $\mathrm{Na}$-mordenite characterized by the $\mathrm{Si} / \mathrm{Al}$ ratio.

The results are shown in Tables 1, 2, 3, and 4 . 


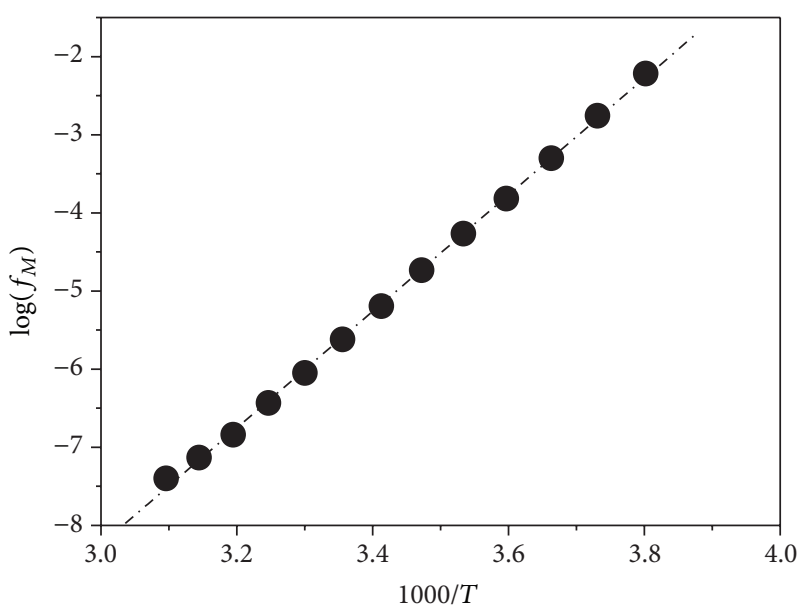

Figure 2: Variation of $\log \left(f_{M}\right)$ depending on $(1000 / T)\left(f_{M}=\omega_{M} /\right.$ $2 \pi$ is the corresponding frequency to the peak of the curve of the permittivity imaginary part $\left(\varepsilon^{\prime \prime}\right)$ measured at various temperatures $(T)$ and expressed in K).

TABLE 1: Number of water molecules $\left(n_{\mathrm{H}_{2} \mathrm{O}}\right)$ adsorbed per cation, in a set of $\mathrm{Na}$-mordenite samples characterized by the $\mathrm{Si} / \mathrm{Al}$ ratio $=5.5$, at each treatment temperature (TT), and the corresponding values of $\Delta E_{\text {ex }}$.

\begin{tabular}{lcc}
\hline $\mathrm{TT}(\mathrm{K})$ & $\begin{array}{c}n_{\mathrm{H}_{2} \mathrm{O} \text { adsorbed }} \\
\text { per cation }\end{array}$ & $\Delta E_{\mathrm{ex}}$ in eV \\
\hline 373 & 1.425 & 0.64 \\
393 & 1.0515 & 0.68 \\
403 & 0.917 & 0.69 \\
413 & 0.808 & 0.71 \\
433 & 0.65 & 0.74 \\
443 & 0.579 & 0.75 \\
453 & 0.518 & 0.75 \\
463 & 0.439 & 0.75 \\
473 & 0.361 & 0.76 \\
\hline
\end{tabular}

TABLE 2: This table shows the experimental variations of $\Delta E_{\mathrm{ex}}$ and the amount of adsorbed water molecules $\left(n_{\mathrm{H}_{2} \mathrm{O}}\right)$ on Na-mordenite samples characterized by the $\mathrm{Si} / \mathrm{Al}$ ratio $=7.92$, at various treatment temperatures (TT).

\begin{tabular}{lcc}
\hline TT $(\mathrm{K})$ & $\begin{array}{c}n_{\mathrm{H}_{2} \mathrm{O} \text { adsorbed }} \\
\text { per cation }\end{array}$ & $\Delta E_{\mathrm{ex}}$ in eV \\
\hline 373 & 1.825 & 0.61 \\
383 & 1.35 & 0.64 \\
393 & 1.301 & 0.67 \\
403 & 1.110 & 0.68 \\
413 & 0.967 & 0.70 \\
423 & 0.861 & 0.71 \\
433 & 0.781 & 0.71 \\
453 & 0.632 & 0.72 \\
473 & 0.476 & 0.72 \\
\hline
\end{tabular}

TABLE 3: Values of experimental variations of $\Delta E_{\mathrm{ex}}$ in relation to the number of adsorbed water molecules $\left(n_{\mathrm{H}_{2} \mathrm{O}}\right)$ on Na-mordenite samples characterized by the $\mathrm{Si} / \mathrm{Al}$ ratio $=9.71$, at various treatment temperatures (TT).

\begin{tabular}{lcc}
\hline TT $(\mathrm{K})$ & $\begin{array}{c}n_{\mathrm{H}_{2} \mathrm{O} \text { adsorbed }} \\
\text { per cation }\end{array}$ & $\Delta E_{\mathrm{ex}}$ in $\mathrm{eV}$ \\
\hline 383 & 1.576 & 0.66 \\
393 & 1.330 & 0.69 \\
403 & 1.147 & 0.71 \\
413 & 1.094 & 0.74 \\
423 & 0.893 & 0.76 \\
433 & 0.804 & 0.77 \\
453 & 0.661 & 0.77 \\
463 & 0.58 & 0.77 \\
\hline
\end{tabular}

TABLE 4: Adsorption of water molecules $\left(n_{\mathrm{H}_{2} \mathrm{O}}\right)$ on Na-mordenite samples characterized by the $\mathrm{Si} / \mathrm{Al}$ ratio $=11.37$ and the corresponding experimental variations in $n_{\mathrm{H}_{2} \mathrm{O}}$ and $\Delta E_{\mathrm{ex}}$ as functions of TT.

\begin{tabular}{lcc}
\hline TT $(\mathrm{K})$ & $\begin{array}{c}n_{\mathrm{H}_{2} \mathrm{O} \text { adsorbed }} \\
\text { per cation }\end{array}$ & $\Delta E_{\text {ex }}$ in eV \\
\hline 403 & 0.964 & 0.70 \\
413 & 0.809 & 0.74 \\
423 & 0.706 & 0.77 \\
433 & 0.527 & 0.78 \\
453 & 0.46 & 0.78 \\
433 & 0.38 & 0.78 \\
\hline
\end{tabular}

\section{Results and Discussion}

3.1. Phenomenological Modelling. It has been an accepted fact for about ten years that the adsorption phenomenon of water on the aluminosilicate surface proceeds in successive steps that were largely described [19-21]. In the present work, we purposely limited our investigations to the domain wherein the number of adsorbed water molecules is not yet high enough for the monolayer to be effective. So we can consider that the solvation phenomenon which leads to the extraction of some cations from the surface does not happen.

Many authors [22-28] have reported simulations using some methods of Monte Carlo and of molecular dynamics, to explain the influence of water molecule adsorption on the energy of the exchanged sodium cations in the hopping process within certain zeolites. Those contributions to the subject are currently fully accepted by the scientific community. Our objective, in this work, consists in using the experimental results of previous work [22-28] to suggest a new empirical method that gives us the opportunity to make use of the obtained experimental results, by studying the adsorption process by means of dielectric relaxation measurement [2934]. Then it should be possible to have new knowledge of the microscopic water molecule adsorption process within the zeolites.

By listing the models used for the simulations [22-28], one sees that, in general, an interaction of Lennard-Jones is 
added to a Coulomb interaction to give the resulting interaction law between a water molecule referred to by the subscript $j$ and the cation $\mathrm{Na}^{+}$referred to by the subscript $k$. We know that the general expression of the Lennard-Jones law [35-37] is as follows:

$$
\Delta E_{\mathrm{L}-\mathrm{J}}=4 \times \Delta \varepsilon_{0, k j}\left[\left(\frac{r_{0, k j}}{r_{k j}}\right)^{12}-\left(\frac{r_{0, k j}}{r_{k j}}\right)^{6}\right],
$$

where $r_{k j}$ is the distance between the two particles (the adsorbed water molecule and the cation) in interaction, $\Delta \varepsilon_{0, k j}$ is an energy, and $r_{0, k j}$ is a distance that characterizes the interaction of Lennard-Jones. In this context, the value of $r_{0, k j}$ is a constant, for a given system.

We also know that the expression of the Coulomb interaction law is formulated as follows:

$$
\Delta E_{C}=\frac{q_{k} \times q_{j}}{4 \pi \varepsilon_{0} \times r_{k j}}
$$

where $r_{k j}$ has the same meaning as in the previous expression, $q_{k}$ and $q_{j}$ are, respectively, the charges carried by the cation and the charge carried by the atom of the water molecule that interacts with the cation, and $\varepsilon_{0}$ is the vacuum permittivity. Then we put down

$$
x_{k j}=\frac{r_{k j}}{r_{0, k j}}
$$

that is simply the expression of the distance between a water molecule $j$ absorbed near a cation and this cation $k$, considering $r_{0, k j}$ to be the unit of length. Then we drew the curve representing the variation of that interaction energy in relation to the distance $x_{k j}$ and we tried to simulate the curve by using the empirical function

$$
\Delta E_{\mathrm{ex}, \mathrm{emp}}=-\left(\frac{C}{x_{k j}}\right)^{m} .
$$

We limited the study to the values of $x_{k j}$ ranging from 1 to 5 , expressed in the chosen unit, because this interval corresponds to the variations obtained experimentally with the distances between exchanged sodium and the oxygen of an adsorbed water molecule, when we studied the adsorption phenomenon by measuring the dielectric relaxation [38-41]. The obtained result is shown in Figure 3. The fit between the two curves seemed very satisfactory, taking into account the uncertainties while determining experimentally the exchanged cation hopping energy.

Now, we can express the change in the energy of a cation hopping related to water molecule adsorption, by a relationship that has the following form:

$$
\Delta E_{\mathrm{ex}}=-\sum_{j}\left(\frac{C}{x_{k j}}\right)^{m} .
$$

This sum of the interaction energies exchanged between a cation and the adsorbed water molecules gives an evaluation

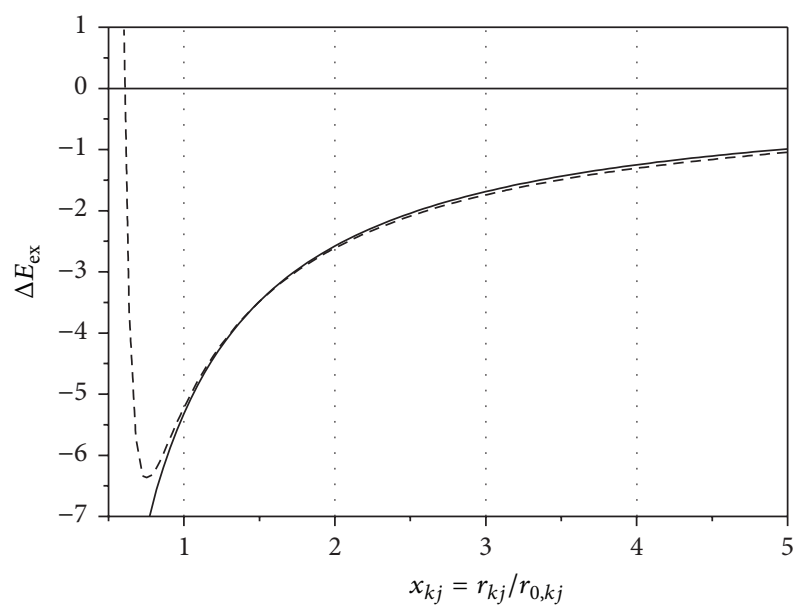

FIGURE 3: Simulation (solid line) by an empirical relation: $\Delta E_{\text {ex,emp }}=$ $-\left(C / x_{k j}\right)^{m}$ of an interaction resulting from the sum of two elemental interactions: a Lennard-Jones interaction on one hand and a Coulomb interaction on the other hand.

of the modification in the necessary energy to extract the cation from its host site (adsorption site). Then classifying the adsorbed water molecules on the basis of their distance to the considered cation and seeing the summation from this angle, it can be expressed in terms of terms as given with (10): the term $x_{k, 1 w}$ standing for the common distances of the $n_{1}$ water molecules adsorbed in the nearest vicinity of the cation and $x_{k, 2 w}$ for the common distances of the $n_{2}$ adsorbed water molecules in the next vicinity of the same cation and so forth:

$$
\begin{aligned}
\Delta E_{\mathrm{ex}} & =\Delta E_{\mathrm{ex}}^{o}-\left[\sum_{i=1}^{n_{1}}\left(\frac{C}{x_{k, 1 w}}\right)^{m}\right. \\
& \left.+\sum_{i=n_{1}+1}^{n_{2}}\left(\frac{C}{x_{k, 2 w}}\right)^{m}+\sum_{i=n_{2}+1}^{N_{\mathrm{H}_{2} \mathrm{O} \text {,toal }}}\left(\frac{C}{x_{k, 3 w}}\right)^{m}\right] .
\end{aligned}
$$

It can be seen that, according to their definition, $x_{k j}$ are scalars. In this description of the adsorption phenomenon, $x_{k, 1 w}$ characterizes the adsorbed molecules that belong to the nearest set to the considered cation; $x_{k, 2 w}$ characterizes the adsorbed molecules that belong to the set adjoining the nearest set to the considered cation. We can write down

$$
\begin{aligned}
& \beta_{2}=\frac{x_{k, 2 w}}{x_{k, 1 w}}, \\
& \beta_{i}=\frac{x_{k, i w}}{x_{k, 1 w}} .
\end{aligned}
$$

Then using

$$
\Delta \varepsilon_{u}=\left(\frac{C}{x_{k, 1 w}}\right)^{m}
$$


and substituting it into (10), we obtain

$$
\begin{aligned}
& \Delta E_{\mathrm{ex}}=\Delta E_{\mathrm{ex}}^{o}-\left[\sum_{i=1}^{n_{1}} \Delta \varepsilon_{u}+\sum_{i=n_{1}+1}^{n_{2}}\left(\frac{1}{\beta_{2}}\right)^{m} \Delta \varepsilon_{u}\right. \\
& \left.+\sum_{i=n_{2}+1}^{N_{\mathrm{H}_{2} \mathrm{O} \text { total }}}\left(\frac{1}{\beta_{3}}\right)^{m} \Delta \varepsilon_{u}\right] .
\end{aligned}
$$

So the variation of $\Delta E_{\mathrm{ex}}$ in relation to the number $\left(n_{\mathrm{H}_{2} \mathrm{O}}\right)$ of the adsorbed water molecules at each degree of advancement can be represented by a curve formed by a series of line segments whose slopes are always negative, with decreasing absolute values corresponding to the term $\left(1 / \beta_{i}\right)^{m}$, where $\beta_{i}$ denote the distances between the cation and the adsorbed water molecules.

Therefore it can be seen that, by opting for this very simple modelling, the interpretation of the curves showing the variations of $\Delta E_{\mathrm{ex}}\left(n_{\mathrm{H}_{2} \mathrm{O}}\right)$ as a function of the number of adsorbed water molecules gains further credit. Indeed, the slopes corresponding to the line segments that we can draw, to split the curves, yield a relative estimate of the respective distances relative to the cation considered as the origin of the positions of the adsorbed water molecules. We can also deduce from it, at every step in the adsorption process, the influence of the water molecules (that fasten onto the surface of the Na-mordenite) on the energy of the exchanged cation hopping. We can compare the information that provides the new interpretation of the curves showing the variation of $\Delta E_{\mathrm{ex}}\left(n_{\mathrm{H}_{2} \mathrm{O}}\right)$ as a function of the number of the adsorbed water molecules with the assumption we previously made for interpreting the experimental results obtained with a series of $\mathrm{Na}$ mordenites. The information that furnishes this new interpretation supports the hypotheses that we previously put forward [38-41]. It is coherent with the results of the simulations conducted in order to explain the same phenomenon [24-26].

\subsection{Interpretation of the Experimental Results}

3.2.1. Na-Mordenites 5.5, 7.92, 9.71, and 11.37. All the curves showing the variations of $\Delta E_{\mathrm{ex}}\left(n_{\mathrm{H}_{2} \mathrm{O}}\right)$, estimated with an accuracy of $0.01 \mathrm{eV}$ in relation to the number of the absorbed water molecules, drawn from the experimental results yielded by the series of $\mathrm{Na}$-mordenites are shown in Figures 4, 5, 6, and 7 .

It can be seen, in Figures 4, 5, 6, and 7, that the splitting into successive line segments always leads us to draw two successive straight lines:

(i) the one corresponding to the first adsorbed water molecules has the lowest slope;

(ii) the latter one characterizing the water molecules subsequently adsorbed has the highest slope (in absolute value).

Table 5 reports the slope values in comparison to the hydration domain of the mordenites. The most dehydrated portion is characterized by a single slope equal to $-0.056 \mathrm{eV} \cdot \mathrm{mol}^{-1} \cdot \mathrm{cat}^{-1}$.

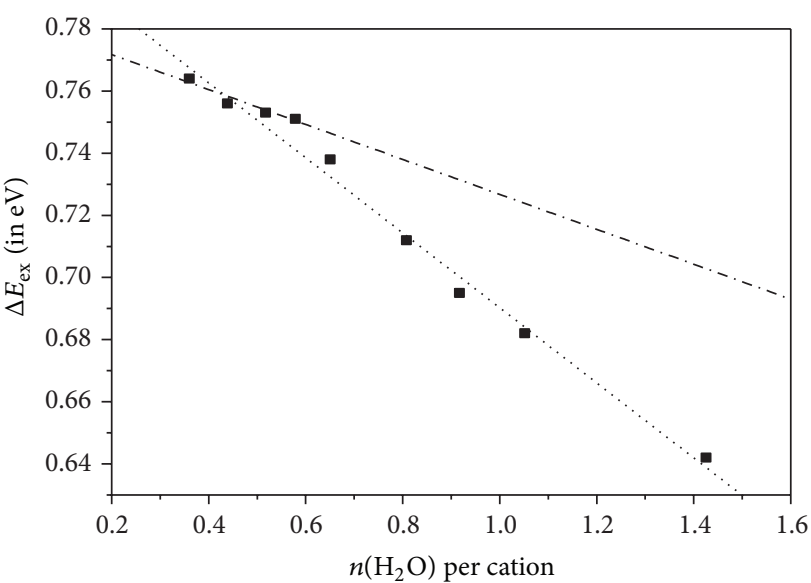

FIGURE 4: Schematic showing the experimental variations of $\Delta E_{\mathrm{ex}}$ as a function of $n_{\mathrm{H}_{2} \mathrm{O}}$ during the adsorption process on a sample of Na-mordenite 5.5.

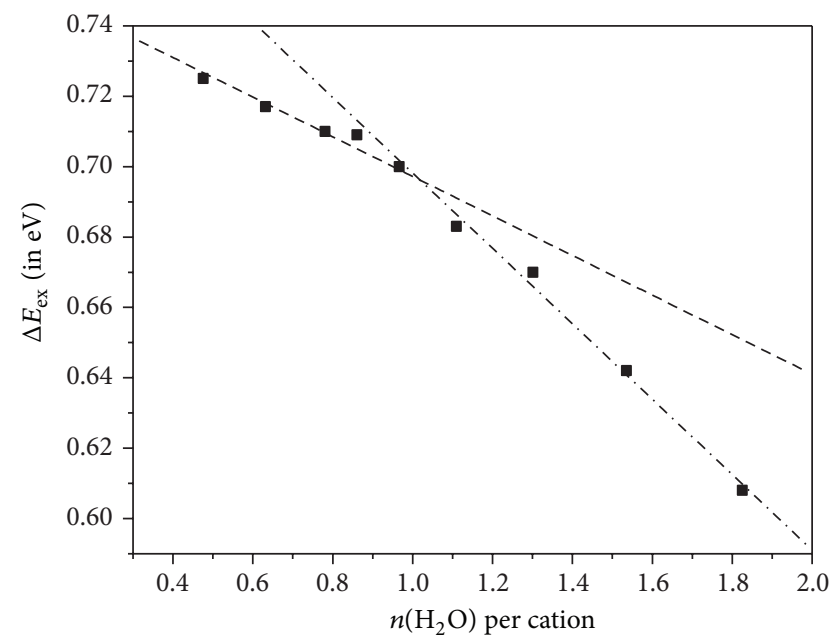

FIGURE 5: Graph of the experimental variation of $\Delta E_{\text {ex }}$ against $n_{\mathrm{H}_{2} \mathrm{O}}$, the amount of adsorbed water molecules on Na-mordenite sample characterized by the $\mathrm{Si} / \mathrm{Al}$ ratio $=7.92$.

\subsection{Comparison between the Influence of the Si/Al Ratio and} That of the Water Vapour Adsorption Process on $\Delta E_{\text {ex }}$. We first determine the variation of $\Delta E_{\mathrm{ex}}$, as a function of the $\mathrm{Si} / \mathrm{Al}$ ratio, in a series of dehydrated $\mathrm{Na}$-mordenite samples of $\mathrm{Si} / \mathrm{Al}$ ratios varying from 5 to 15 including those of the $\mathrm{Si} / \mathrm{Al}$ ratios studied in the present work (see Figure 8). Thus, the values of $\Delta E_{\text {ex }}$ determined by dielectric relaxation measurement in a series of dehydrated Na-mordenites can be considered as a parameter that characterizes the $\mathrm{Si} / \mathrm{Al}$ ratio of each studied sample.

While considering the results relating to the hydrated mordenites, we included the values in which we are interested in Table 6 wherein we also included the slopes of the curves representing $\Delta E_{\mathrm{ex}}$ (in $\left.\mathrm{eV}\right)=f\left(n_{\mathrm{H}_{2} \mathrm{O}}\right)$ determined while observing the second step (highest slopes) in the adsorption of water molecules on the corresponding zeolites.

As illustrated by Figure 8, when we plot these results, they show without ambiguity that the rise in the $\mathrm{Si} / \mathrm{Al}$ ratio 
TABLE 5: Slopes of the line segments that form the curve representing $\Delta E_{\text {ex }}$ (in eV) $=f\left(n_{\mathrm{H}_{2} \mathrm{O}}\right)$ and the corresponding domain of the number of adsorbed water molecules.

\begin{tabular}{|c|c|c|c|}
\hline Adsorption domain & $\begin{array}{c}0.3<n_{\mathrm{H}_{2} \mathrm{O}}<0.6 \\
\text { On the whole observed Na-mordenites }\end{array}$ & & $\begin{array}{c}0.6<n_{\mathrm{H}_{2} \mathrm{O}}<1.2 \\
\text { Na-mordenite } 5.5\end{array}$ \\
\hline Slope & $\begin{array}{c}-\mathbf{0 . 0 5 6} \\
(\text { common })\end{array}$ & & -0.120 \\
\hline Adsorption domain & $\begin{array}{c}0.9<n_{\mathrm{H}_{2} \mathrm{O}}<1.8 \\
\text { Na-mordenite } 7.92\end{array}$ & $\begin{array}{c}1<n_{\mathrm{H}_{2} \mathrm{O}}<1.6 \\
\text { Na-mordenite } 9.71\end{array}$ & $\begin{array}{c}0.75<n_{\mathrm{H}_{2} \mathrm{O}}<1 \\
\text { Na-mordenite } 11.37\end{array}$ \\
\hline Slope & -0.107 & -0.156 & -0.275 \\
\hline
\end{tabular}

TABLE 6: Values of $\Delta E_{\text {ex }}$ corresponding to the completely dehydrated state, and reminder of the corresponding highest slopes, after hydration process (Table 5).

\begin{tabular}{lcccc}
\hline Si/Al ratio & 5.5 & 7.92 & 9.71 & \\
\hline$\Delta E_{\text {ex }}($ in eV) & 0.67 & 0.70 & 0.72 & 0.74 \\
Slope & -0.120 & -0.107 & -0.156 & -0.275 \\
\hline
\end{tabular}

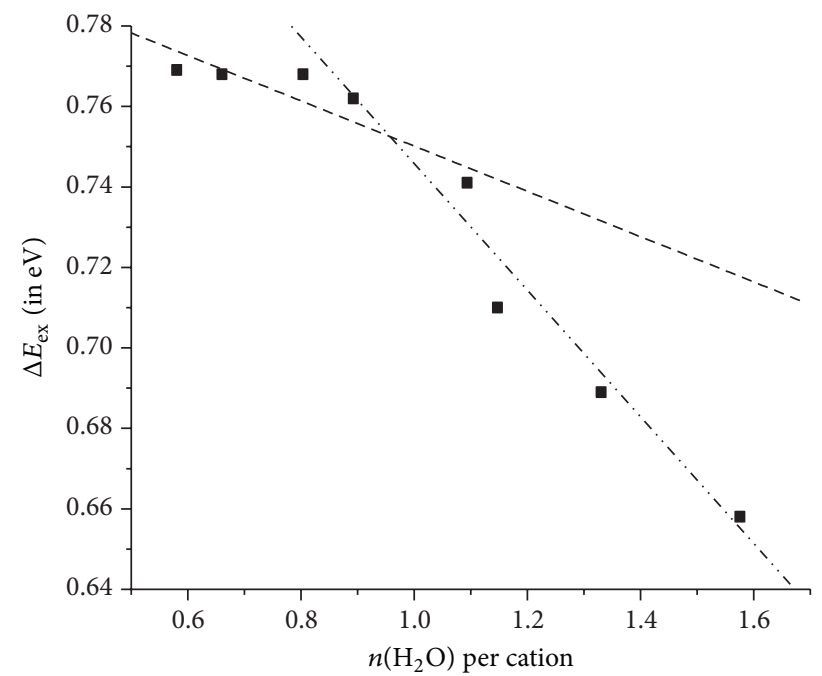

FIgURE 6: Variation of the experimental $\Delta E_{\text {ex }}$ with change in the number $\left(n_{\mathrm{H}_{2} \mathrm{O}}\right)$ of adsorbed water molecules on a sample of $\mathrm{Na}$ mordenite 9.71 .

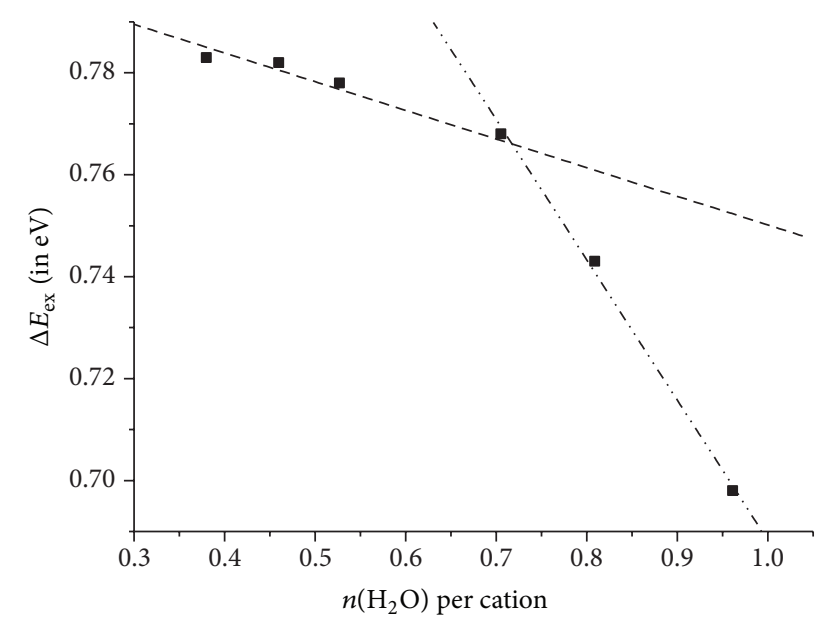

FIGURE 7: Relation between the experimental variation of $\Delta E_{\text {ex }}$ and the number $\left(n_{\mathrm{H}_{2} \mathrm{O}}\right)$ of adsorbed water molecules on Na-mordenite sample characterized by the $\mathrm{Si} / \mathrm{Al}$ ratio $=11.37$.

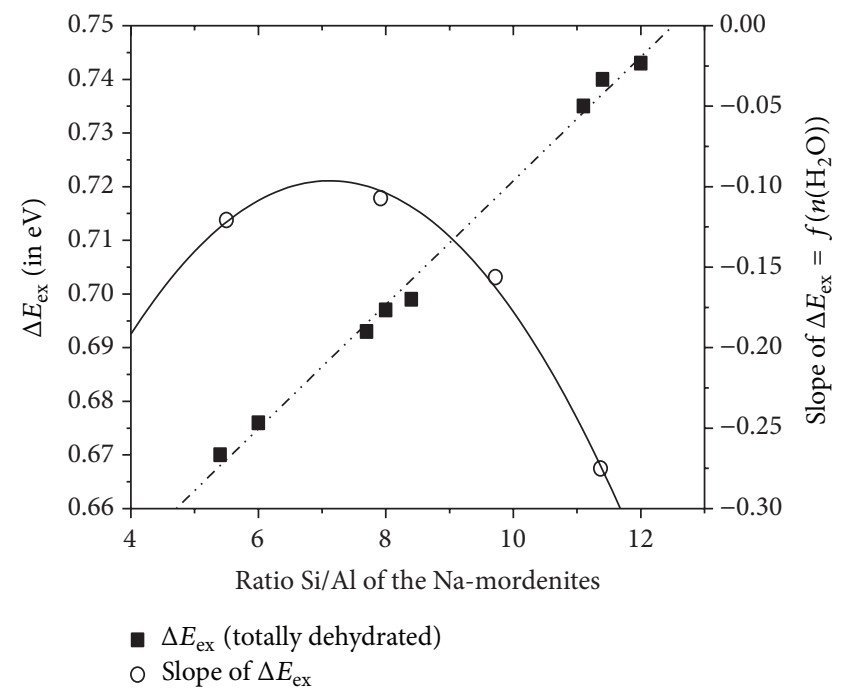

FIGURE 8: Comparison between the influences of the Si/Al ratio on $\Delta E_{\mathrm{ex}}$ and on the modifications of the energy $\left(\Delta E_{\mathrm{ex}}\right)$ by the water vapour adsorption process.

is accompanied by a concomitant increase in the cation hopping energy within the dehydrated Na-mordenites. They also show clearly that, above 7.3 , the $\mathrm{Si} / \mathrm{Al}$ ratio influences markedly the interaction of the water molecules adsorbed during the second step in the adsorption (highest slopes), with the exchangeable cations. Indeed, we see in Figure 8 that, beyond 7.3, the more the $\mathrm{Si} / \mathrm{Al}$ ratio increases the quicker and deeper the cation hopping energy is modified by the water molecules adsorbed during the second step in the adsorption. That means that when the $\mathrm{Si} / \mathrm{Al}$ ratio is high, the adsorbed water molecules come rapidly and disturb strongly the cation hopping energy. We can infer that beyond 7.3 the increase in the $\mathrm{Si} / \mathrm{Al}$ ratio within the $\mathrm{Na}$-mordenites is the expression of a higher affinity of the water molecules for the exchangeable cations.

The information that furnishes this new interpretation confirms the hypotheses put forward beforehand. And it 


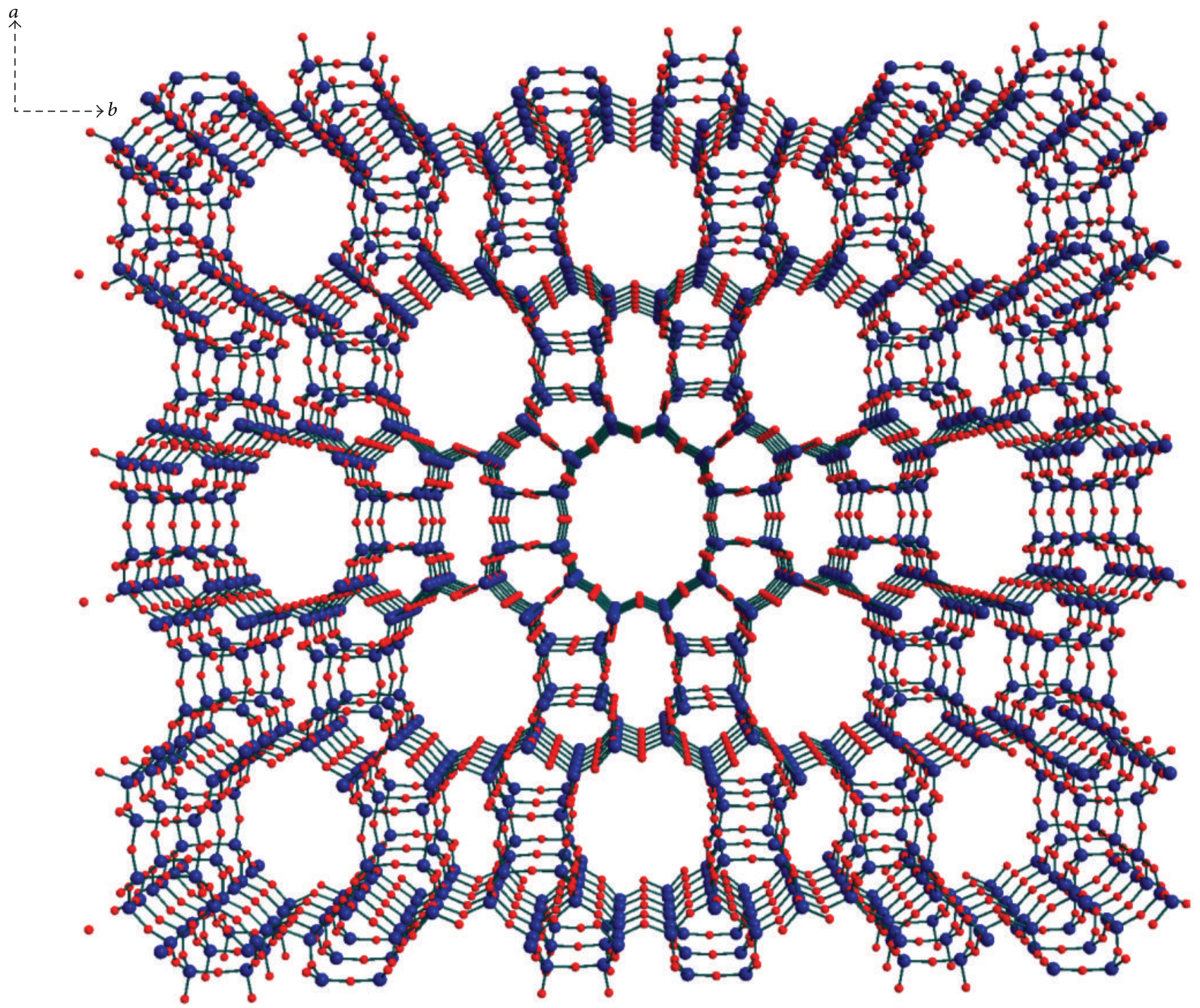

FIGURE 9: Orthorhombic structure of the mordenite characterized by the presence of pores.

is also coherent with the results of the simulations carried out for explaining the same phenomenon. The interpretation that we suggest here enables deducing the influence, on the exchanged cation hopping energy, of the water molecules absorbed on the Na-mordenite surface at every step in the adsorption process.

3.4. Structural Illustration of the Modelling. The physicochemical properties of the mordenite that belongs to zeolite family of minerals are strongly related to the crystal structure, characterized by a unit cell whose general formula is $\left(\mathrm{M}^{n+}\right)_{x / n} \mathrm{Al}_{x} \mathrm{Si}_{48-x} \mathrm{O}_{96}, y \mathrm{H}_{2} \mathrm{O}$, where $\mathrm{M}$ is a compensation alkaline cation or a compensation alkaline earth cation, whose valency is worth $n$. Thus the mordenite is an aluminosilicate made up of an assembly of $\left[\mathrm{SiO}_{4}{ }^{4-}\right]$ tetrahedra and $\left[\mathrm{AlO}_{4}{ }^{5-}\right]$ tetrahedra sharing the oxygen atoms at their corners. This organization of tetrahedra displays, within the created structure, two types of molecular-sized channels [42-44]:

(i) the principal channels parallel to the axis $c$;

(ii) the secondary channels parallel to the axis $b$ that appear on the principal channels and are connected between them through the lateral cavities.

Figure 9 shows the structure of the mordenite that crystallizes in the orthorhombic system and belongs to the space group $\mathrm{Cmcm}$ or $\mathrm{Cmc}$. It shows clearly the presence of channels that constitute it and allow it to develop a high surfacearea accessible to the molecules capable of diffusing through the pores of the crystal lattice.

On a microscopic level, there are four types of crystallographic sites, occupied by aluminium or silicium atoms. The cations are located in the specific sites, numbered from I to VI, following Mortier's crystallographic site classification 

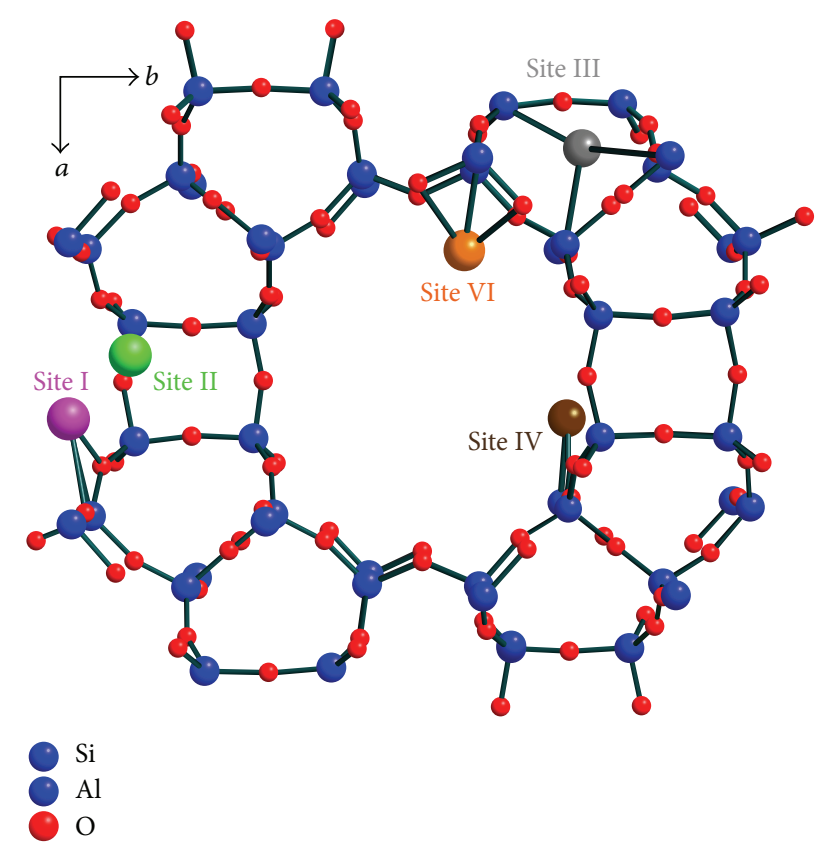

FIgURE 10: Representation of the different cationic sites in the mordenite labelled according to Mortier's classification system [45].

system [45], as one goes from the small channel (site I) towards the big channel (site VI), via the lateral cavities (sites II, III, and IV). Figure 10 shows a representation of the mordenite unit cell with the different cationic sites within it.

However, all the cationic sites are not occupied. Their occupancy depends strongly upon the characteristic of the considered cation (size, polarizability) but also upon some structural properties of the host crystal lattice [46-53]. In the case of the sodium mordenite of $\mathrm{Si} / \mathrm{Al}$ ratio equal to 5.5 , the occupancy rates $[9,54-57]$ of sites I, II, III, IV, and VI are, respectively, 3.1, negligible, negligible, 2.6, and 1.5.

Site I with octahedral coordination is stable and its geometry leaves a tight room for the cation to move about. Its occupancy brings about a blocking of the lateral cavities and isolation of the principal channels from each other [58].

Site IV is hexacoordinated and has a planar structure. It is much less stable than site one and is located at the entry of the lateral cavities. This position leaves a space to the big principle channel, thus promoting the mobility of the cation that occupies it.

As for site VI, it possesses a pyramidal geometry with a square base. It is located in the big principal channel and has a very open framework structure.

The change in the ratio $\mathrm{Si} / \mathrm{Al}$ influences the physicalchemical properties of the mordenite. A decrease in the number of the aluminium atoms within the crystal lattice leads to a higher resistance at high temperature and brings about a hydrophobic characteristic [59-63].

The structure of the mordenite shows that each atom belonging to it is sufficiently close to a channel or pore to be involved in the surface properties of the solid.

The samples we have studied are of $\mathrm{Si} / \mathrm{Al}$ ratios equal to $5.5,7.92,9.71$, and 11.37 corresponding to the number

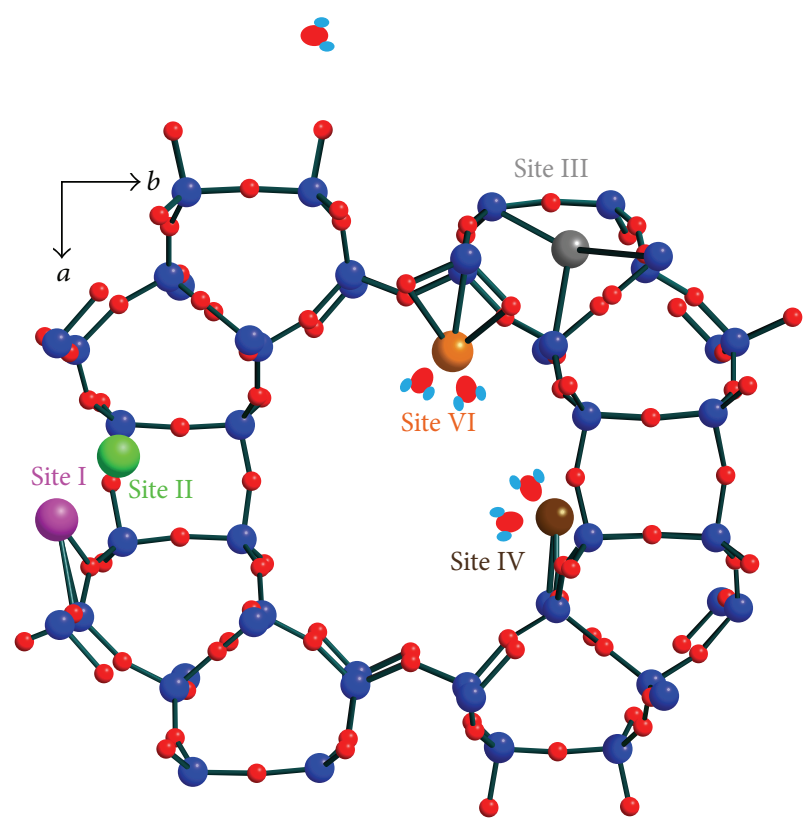

$\bigodot_{\mathrm{O}}^{\mathrm{Al}}$

FIGURE 11: Structural illustration of the modelling presented in Section 3.1.

of aluminium atoms per unit cell equal to, respectively, 8, 6,5 , and 4 . The smaller the $\mathrm{Si} / \mathrm{Al}$ ratio is, the more the sodium mordenite adsorbs hydrophilic molecules. In the course of the adsorption phenomenon of water by the sodium mordenite, the first water molecules attach themselves in the vicinity of sodium ion that can be found in the big channels where the distance that separates exchangeable cation is the greatest possible, as is shown in Figure 11 where some adsorbed water molecules (denoted by a v-shaped set of three coloured circles adjacent to one another) are represented.

Then we can compare the information that yields the new interpretation of the curves showing the variations of $\Delta E_{\mathrm{ex}}\left(n_{\mathrm{H}_{2} \mathrm{O}}\right)$ depending on the number of adsorbed water molecules with the hypotheses we put forward previously, in order to interpret other experimental results that we obtained with the Na-mordenite.

\section{Conclusion}

In this work, we have shown how the use of the complex impedance spectroscopy allows characterizing the evolution of the surface properties of microporous solids according to the water molecules adsorption process. The studies that we previously performed on the same materials in a dehydrated state [9-12] led us to discuss the nature of the energy driving the exchangeable cation hopping between two adjoining sites onto the surface of the zeolite. The obtained results by dielectric relaxation method make it possible to determine the change in the energy according to the number of adsorbed water molecules. Then we see that it is possible to account for 
these changes on the one hand by using a relationship called Polanyi law [5] that describes the successive equilibrium states that characterize the adsorption process and on the other hand by making a series of assumptions on the distribution of water molecules adsorbed in the neighbourhood of the exchangeable cations trapped on the sample surface. These assumptions were developed from previous experimental studies, whose aim consisted in observing, by using various techniques, the same type of sample submitted to the same phenomenon. Then we were able to compare the respective adsorption behaviours, according to the number of adsorbed water molecules, the results that we experimentally obtained, on the one hand, and some values of the hopping energy derived from the theoretical expression, deduced from the previous hypotheses, on the other hand. Then we observe that the two behaviours are consistent. The resulting fact, in our opinion, is that this contribution shows which kind of information the study of the adsorption phenomenon, by means of dielectric relaxation, can allow us to know. Thus this method yields essentially a qualitative description of the distribution of water molecules adsorbed on the surface of a Na-mordenite sample.

\section{Conflict of Interests}

The author declares that there is no conflict of interests regarding the publication of this paper.

\section{Acknowledgments}

The author would like very much to thank Professor J. V. Zanchetta (honorary professor at University of Montpellier 2, France) and Professor J. C. Giuntini (honorary professor at University of Montpellier 2, France) for the Dielectric Relaxation Spectroscopy (DRS) facility and for their support.

\section{References}

[1] R. M. Barrer, Zeolites and Clay Minerals as Sorbents and Molecular Sieves, Academic Press, New York, NY, USA, 1978.

[2] A. K. Cheetham and P. Day, Solid State Chemistry: Compounds, Oxford University Press, Oxford, UK, 1992.

[3] G. Olhmann, J. C. Vedrine, and P. A. Jacobs, Catalysis and Adsorption by Zeolites, Elsevier, Amsterdam, The Netherlands, 1991.

[4] S. Brunauer, Physical Adsorption of Gases and Vapors, Princeton University PressPrinceton University Press, Princeton, NJ, USA, 1945.

[5] M. Polanyi, "Causes of forces of adsorption," Zeitschrift für Elektrochemie, vol. 26, pp. 370-374, 1920.

[6] R. Defaye and I. Prigogine, Tension Superficielle et Adsorption, Dunod, Paris, France, 1951.

[7] G. O. Wood, "Affinity coefficients of the Polanyi/Dubinin adsorption isotherm equations. A review with compilations and correlations," Carbon, vol. 39, no. 3, pp. 343-356, 2001.

[8] R. Defaye, I. Prigogine, and A. Bellemans, Surface Tension and Adsorption, Wiley, New York, NY, USA, 1966.

[9] S. Devautour, J. Vanderschueren, J. C. Giuntini, F. Henn, J. V. Zanchetta, and J. L. Ginoux, "Na ${ }^{+} /$mordenite interaction energy determined by thermally stimulated depolarization current," The Journal of Physical Chemistry B, vol. 102, no. 19, pp. 37493753, 1998.

[10] J. C. Giuntini, G. Maurin, S. Devautour, F. Henn, and J. V. Zanchetta, "Experimental evidence of polarization effects on exchangeable cations trapped in zeolites," Journal of Chemical Physics, vol. 113, no. 11, pp. 4498-4500, 2000.

[11] J. C. Giuntini, V. Mouton, J. V. Zanchetta, J. M. Douillard, J. Niezette, and J. Vanderschueren, "A simple general relationship between the dielectric losses measured on divided solids and adsorption thermodynamic," Langmuir, vol. 13, no. 5, pp. 10161019, 1997.

[12] G. Rodríguez-Fuentes, S. Devautour-Vinot, S. Diaby, and F. Henn, "Insights into cation exchange selectivity of a natural clinoptilolite by means of dielectric relaxation spectroscopy," Physics and Chemistry of Minerals, vol. 38, no. 8, pp. 613-621, 2011.

[13] S. R. Elliott, "Temperature dependance of ac conductivity of chalcogenide glasses," Philosophical Magazine B, vol. 37, no. 5, pp. 553-560, 1978.

[14] B. K. P. Scaife, Principles of Dielectrics, Oxford Science Publications, 1998.

[15] Y.-Z. Wei and S. Sridhar, "A new graphical representation for dielectric data," The Journal of Chemical Physics, vol. 99, no. 4, pp. 3119-3124, 1993.

[16] J. R. Macdonald, "Dispersed electrical-relaxation response: discrimination between conductive and dielectric relaxation processes," Brazilian Journal of Physics, vol. 29, no. 2, pp. 332-346, 1999.

[17] A. Abdel- Aal, "Dielectric relaxation in $\mathrm{Cd}_{\mathrm{x}} \mathrm{InSe}_{9-\mathrm{x}}$ chalcogenide thin films," Egyptian Journal of Solids, vol. 29, no. 2, pp. 303-316, 2006.

[18] A. Dey, A. De, and S. K. De, "Electrical transport and dielectric relaxation in $\mathrm{Fe}_{3} \mathrm{O}^{4-}$ polypyrrole hybrid nanocomposites," Journal of Physics Condensed Matter, vol. 17, no. 37, pp. 5895-5910, 2005.

[19] J. M. Cases, I. Bérend, G. Besson et al., "Mechanism of adsorption and desorption of water vapor by homoionic montmorillonite. 1. The sodium-exchanged form," Langmuir, vol. 8, no. 11, pp. 2730-2739, 1992.

[20] I. Bérend, J.-M. Cases, M. François et al., "Mechanism of adsorption and desorption of water vapor by homoionic montmorillonites. 2. The $\mathrm{Li}^{+}, \mathrm{Na}^{+}, \mathrm{K}^{+}, \mathrm{Rb}^{+}$and the $\mathrm{Cs}^{+}$exchanged forms," Clays and Clay Minerals, vol. 43, no. 3, pp. 324-336, 1995.

[21] J. M. Cases, I. Bérend, M. François, J. P. Uriot, L. J. Michot, and F. Thomas, "Mechanism of adsorption and desorption of water vapor by homoionic montmorillonite: 3 . The $\mathrm{Mg}^{2+}, \mathrm{Ca}^{2+}, \mathrm{Sr}^{2+}$ and $\mathrm{Ba}^{2+}$ exchanged forms," Clays and Clay Minerals, vol. 45, no. 1, pp. 8-22, 1997.

[22] G. D. Halsey, "Physical adsorption on non-uniform surfaces," The Journal of Chemical Physics, vol. 16, no. 10, pp. 931-937, 1948.

[23] T. L. Hill, “Theory of physical adsorption," Advances in Catalysis, vol. 4, pp. 211-258, 1952.

[24] G. Maurin, R. G. Bell, S. Devautour, F. Henn, and J. C. Giuntini, "Modelling the effect of hydration in zeolite $\mathrm{Na}^{+}$-Mordenite," Journal of Physical Chemistry B, vol. 108, no. 12, pp. 3739-3745, 2004.

[25] D. F. Plant, G. Maurin, H. Jobic, and P. L. Llewelyn, "Molecular dynamics simulation of the cation motion upon adsorption of $\mathrm{CO}_{2}$ in Faujasite zeolite systems," The Journal of Physical Chemistry B, vol. 110, no. 29, pp. 14372-14378, 2006. 
[26] J. C. Giuntini, J. M. Douillard, G. Maurin, S. Devautour-Vinot, A. Nicolas, and F. Henn, "Aluminosilicate surface energy and its evolution upon adsorption using dielectric relaxation spectroscopy," Chemical Physics Letters, vol. 423, no. 1-3, pp. 71-75, 2006.

[27] A. G. Bezus, A. V. Kiselev, A. A. Lopatkin, and P. Q. Du, "Molecular statistical calculation of the thermodynamic adsorption characteristics of zeolites using the atom-atom approximation. Part 1-Adsorption of methane by zeolite NaX," Journal of the Chemical Society Faraday Transactions 2, vol. 74, pp. 367-379, 1978.

[28] J. Karger and D. M. Ruthven, Diffusion in Zeolites and Other Microporous Solids, Willey Interscience, New York, NY, USA, 1992.

[29] S. R. Elliott, "A theory of ac conduction in chalcogenide glasses," Philos Mag, vol. 36, no. 6, pp. 1291-1304, 1977.

[30] C. J. F. Bottcher and P. Bordewijk, Theory of Electric Polarization, Elsevier, Amsterdam, The Netherlands, 1978.

[31] N. F. Mott and E. A. Davis, Electronics Processes in Non-Cristalline Materials, Clarendon, Oxford, UK, 1979.

[32] N. Musahwar, M. A. Majeed Khan, M. Husain, and M. Zulfequar, "Dielectric and electrical properties of Se-S glassy alloys," Physica B: Condensed Matter, vol. 396, no. 1-2, pp. 81-86, 2007.

[33] J. R. Macdonald, Impedances Spectroscopy, Mac Donald-John Wiley \& Sons, New York, NY, USA, 1987.

[34] A. K. Jonscher, Dielectric Relaxation in Solids, Chelsea Dielectrics Press, London, UK, 1983.

[35] R. H. Fowler and E. A. Guggenheim, Statistical Thermodynamics, Cambridge University Press, Cambridge, UK, 1939.

[36] D. M. Deaven, N. Tit, J. R. Morris, and K. M. Ho, "Structural optimization of Lennard-Jones clusters by a genetic algorithm," Chemical Physics Letters, vol. 256, no. 1-2, pp. 195-200, 1996.

[37] D. J. Wales and J. P. K. Doye, "Global optimization by basinhopping and the lowest energy structures of Lennard-Jones clusters containing up to 110 atoms," Journal of Physical Chemistry A, vol. 101, no. 28, pp. 5111-5116, 1997.

[38] G. Maurin, P. Senet, S. Devautour et al., "Combining the Monte Carlo technique with 29SI NMR spectroscopy: simulations of cation locations in zeolites with various $\mathrm{Si} / \mathrm{Al}$ ratios," Journal of Physical Chemistry B, vol. 105, no. 38, pp. 9157-9161, 2001.

[39] J. M. Douillard, G. Maurin, F. Henn, S. Devautour-Vinot, and J. C. Giuntini, "Use of dielectric relaxation for measurements of surface energy variations during adsorption of water on mordenite," Journal of Colloid and Interface Science, vol. 306, no. 2, pp. 440-448, 2007.

[40] A. Nicolas, S. Devautour-Vinot, G. Maurin, J. C. Giuntini, and F. Henn, "Location and de-trapping energy of sodium ions in dehydrated $\mathrm{X}$ and $\mathrm{Y}$ faujasites determined by dielectric relaxation spectroscopy," Microporous and Mesoporous Materials, vol. 109, no. 1-3, pp. 413-419, 2008.

[41] M. Kharroubi, S. Balme, A. Haouzi, H. Belarbi, D. Sekou, and F. Henn, "Interlayer cation-water thermodynamics and dynamics in homoionic alkali and alkaline-earth exchanged montmorillonites with low water loadings," Journal of Physical Chemistry C, vol. 116, no. 28, pp. 14970-14978, 2012.

[42] W. M. Meier, "The crystal structure of mordenite (ptilolite) ${ }^{*}$," Zeitschrift für Kristallographie, vol. 115, no. 5-6, pp. 439-450, 1961.

[43] V. Graemlich, Untersuchung und Verfeinerung pseudosymmetrischer Strukturen [Ph.D. thesis], ETH, Zurich, Switzerland, 1971.
[44] W. Lowenstein, "The distribution of aluminum in the tetrahedra of silicates and aluminates," American Mineralogist, vol. 39, pp. 92-96, 1954.

[45] W. J. Mortier, Compilation of Extraframework Sites in Zeolites, Butterworths, Guildford, UK, 1982.

[46] K. Shiokawa, M. Ito, and K. Itabashi, "Crystal structure of synthetic mordenites," Zeolites, vol. 9, no. 3, pp. 170-176, 1989.

[47] W. J. Mortier, J. J. Pluth, and J. V. Smith, "Positions of cations and molecules in zeolites with the mordenite-type framework I dehydrated Ca-exchanged ptilolite," Materials Research Bulletin, vol. 10, no. 10, pp. 1037-1045, 1975.

[48] W. J. Mortier, J. J. Pluth, and J. V. Smith, "Positions of cations and molecules in zeolites with the mordenite-type framework II dehydrated hydrogen-ptilolite," Materials Research Bulletin, vol. 10, no. 12, pp. 1319-1325, 1975.

[49] W. J. Mortier, J. J. Pluth, and J. V. Smith, "Positions of cations and molecules in zeolites with the mordenite-type framework. III Rehydrated Ca-exchanged ptilolite," Materials Research Bulletin, vol. 11, no. 1, pp. 15-21, 1976.

[50] J. L. Schlenker, J. J. Pluth, and J. V. Smith, "Positions of cations and molecules in zeolites with the mordenite-type framework. V dehydrated Rb-mordenite," Materials Research Bulletin, vol. 13, no. 1, pp. 77-82, 1978.

[51] J. L. Schlenker, J. J. Pluth, and J. V. Smith, "Positions of cations and molecules in zeolites with the mordenite-type framework VI dehydrated barium mordenite," Materials Research Bulletin, vol. 13, no. 3, pp. 169-174, 1978.

[52] J. L. Schlenker, J. J. Pluth, and J. V. Smith, "Positions of cations and molecules in zeolites with the mordenite-type framework VII dehydrated cesium mordenite," Materials Research Bulletin, vol. 13, no. 9, pp. 901-905, 1978.

[53] J. L. Schlenker, J. J. Pluth, and J. V. Smith, "Positions of cations and molecules in zeolites with the mordenite-type framework. VIII dehydrated sodium-exchanged mordenite," Materials Research Bulletin, vol. 14, no. 6, pp. 751-758, 1979.

[54] C. G. Coe and S. M. Kuznicki, U.S. Patent 4,481,018, 1984.

[55] L. V. C. Rees, The Properties and Applications of Zeolites, R. P. Townsend Edition, Special Publication no. 33, The Chemical Society, London, UK, 1980.

[56] R. P. Townsend, "Ion exchange in zeolites: some recent developments in theory and practice," Studies in Surface Science and Catalysis, vol. 28, pp. 273-282, 1986.

[57] J. A. Gray and J. T. Cobb Jr., "Hydroisomerization and hydrocracking of normal pentane over various mordenite catalysts," Journal of Catalysis, vol. 36, no. 2, pp. 125-141, 1975.

[58] B. Coughlan, W. M. Carroll, and W. A. McCann, "Water in homoionic and heteroionic mordenites: a calorimetric study. Part 1.- alkali and alkaline earth metal forms," Journal of the Chemical Society, Faraday Transactions 1: Physical Chemistry in Condensed Phases, vol. 73, pp. 1612-1621, 1977.

[59] D. W. Breck, Zeolite Molecular Sieves: Structure, Chemistry and Use, John Wiley \& Sons, New York, NY, USA, 1974.

[60] H. G. Karge and J. Weitkamp, Synthesis, vol. 1 of Molecular Sieves-Science and Technology, Springer, Berlin, Germany, 1998.

[61] A. Dyer, An Introduction to Zeolite Molecular Sieves, John Wiley, New York, NY, USA, 1988.

[62] W. M. Meier, D. H. Olson, and Ch. Baerlocher, Atlas of Zeolite Structure Types, Elsevier, London, UK, 4th edition, 1996.

[63] G. Gottardi and E. Galli, Natural Zeolites, Springer, Berlin, Germany, 1985. 

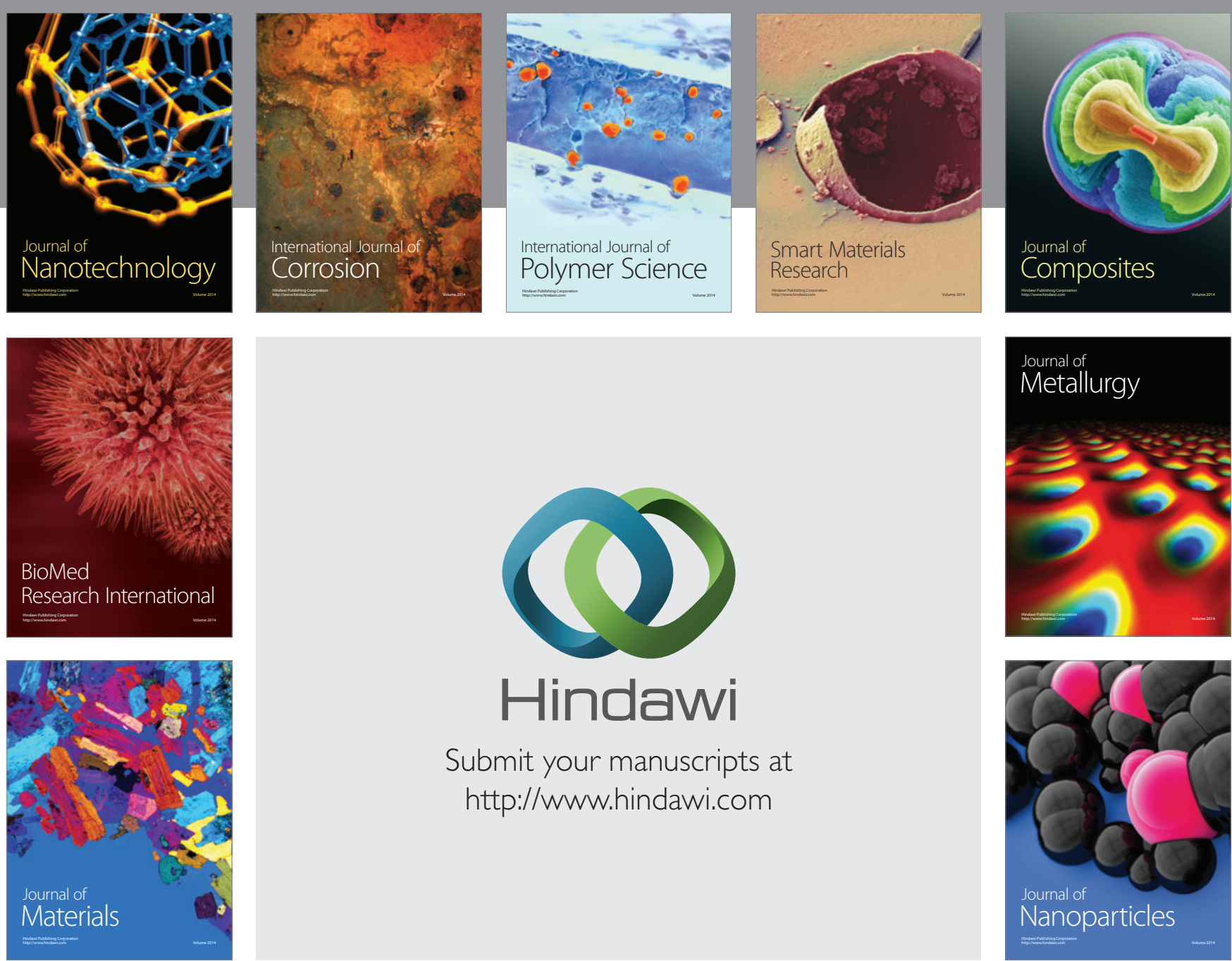

\section{Hindawi}

Submit your manuscripts at

http://www.hindawi.com

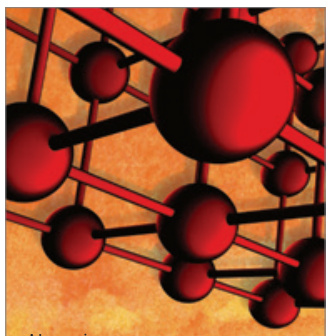

Materials Science and Engineering
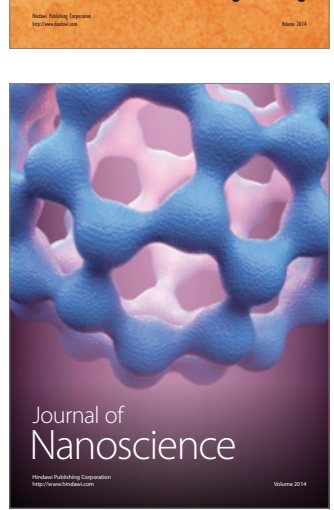
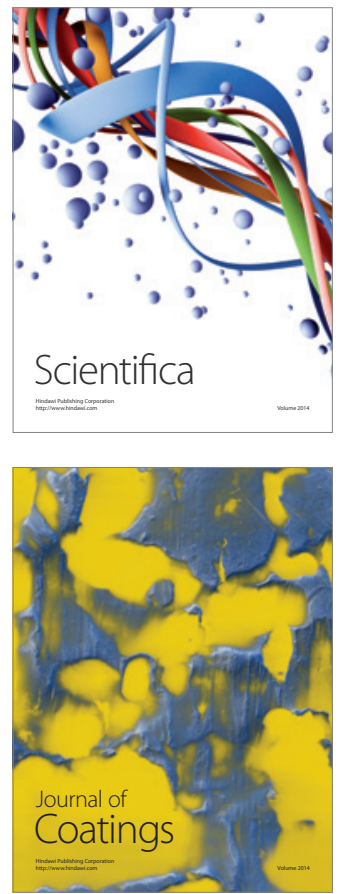
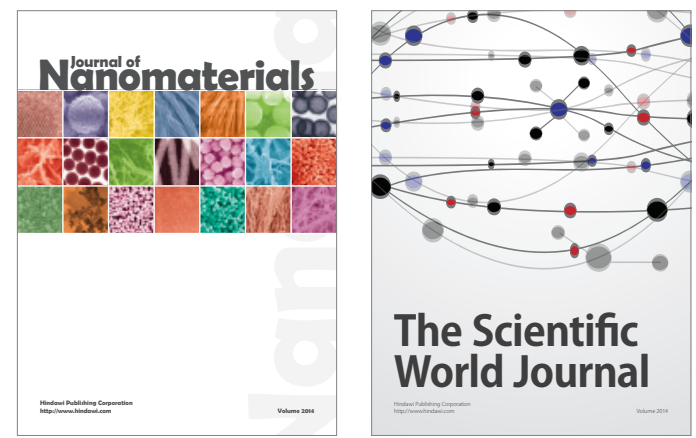

The Scientific World Journal
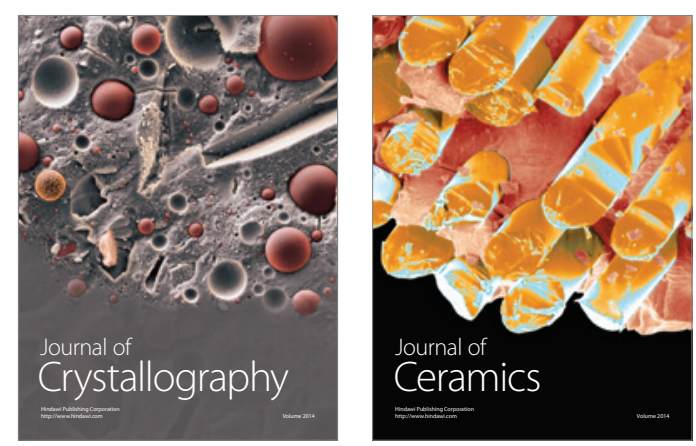
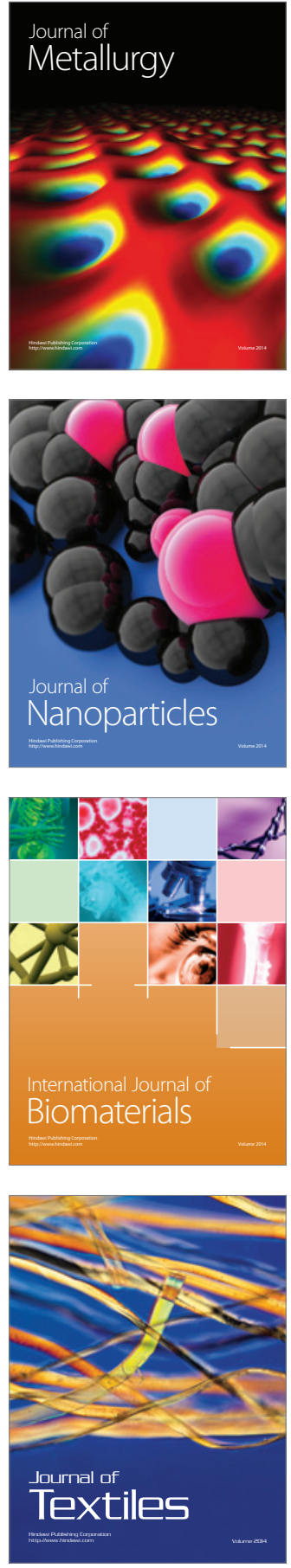